\title{
As transações entre supermercados europeus e produtores brasileiros de frutas frescas
}

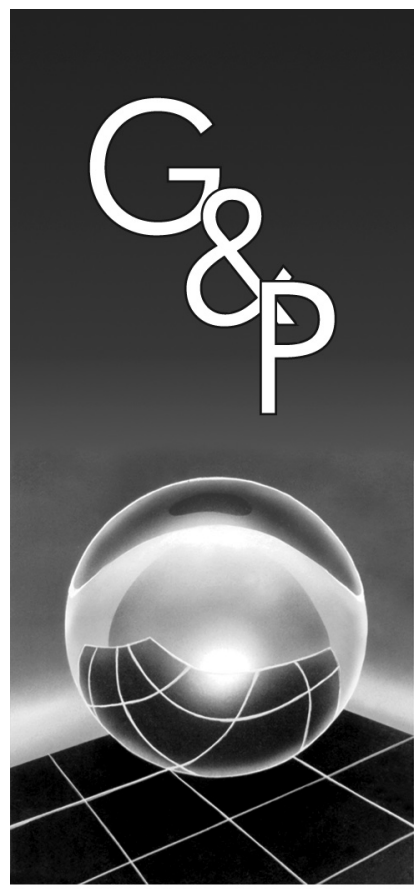

Roberta de Castro Souza

João Amato Neto

\section{Resumo}

Vários autores apontam a importância do segmento varejista como indutor de mudanças nas cadeias produtivas de diferentes produtos. Particularmente, no que diz respeito às cadeias produtivas de frutas frescas pode-se observar a importância do segmento varejista como indutor de padrões de qualidade e de uma série de mudanças que se revelam por meio de ações tomadas pelos outros segmentos de maneira a atender suas exigências. No entanto, não há estudos que mostrem qual a intensidade desta ação e quais os elementos que podem influenciá-la. Sendo assim, o objetivo deste trabalho é caracterizar as transações entre produtores brasileiros de manga e uva e compradores europeus e as estruturas das cadeias de valor de manga e uva para exportação. Na parte conceitual foi utilizada a abordagem de Cadeia de Valor Global e de Economia dos Custos de Transação. O método escolhido foi o estudo de casos múltiplos, conduzido com duas cadeias produtivas, a de uva e a de manga, voltadas para exportação para o mercado europeu. Foram conduzidas entrevistas presenciais com produtores e exportadores brasileiros de manga e uva, bem como com importadores alemães, ingleses e holandeses, no período de 2004 a 2005. Os resultados indicam que os supermercados atuam de maneira diferenciada nos dois mercados estudados, o inglês e alemão. Nas transações entre supermercados ingleses na cadeia de valor de frutas frescas com produtores brasileiros há o gerenciador de categoria que é o agente responsável pela ligação entre produtores brasileiros e supermercados ingleses e predominam estruturas de governança híbridas. Já no mercado alemão, não há o gerenciador de categoria e predomina a estrutura de governança de mercado. Estas diferenças nas estruturas das cadeias de valor nos dois mercados têm implicações diretas na maneira de inserção dos produtores de frutas frescas de países em desenvolvimento no comércio global.

Palavras-chave: Governança. Supermercados. Frutas in natura.

\section{Introdução}

Uma das maiores tendências das cadeias produtivas de alimentos é a questão da concentração do segmento varejista. Este fato tem várias consequências para os outros segmentos que compõem as cadeias de alimentos e dentre eles pode-se ressaltar a questão do aumento das exigências quanto ao padrão de qualidade. $\mathrm{O}$ aumento das exigências faz com que os fornecedores devam se adequar às novas regras de maneira a atendê-las: fazer investimentos em infraestrutura, treinamento e adotar certificados. Um outro elemento é que a estrutura de fornecimento dos supermercados está extremamente globalizada com fornecedores espalhados no mundo todo (FULPONI, 2006; JAFFEE; MASAKURE, 2005; GARCIA; POOLE, 2004; HUMPHREY, 2005). Apesar de haver fornecedores locais, principalmente para produtos frescos, já é fundamental a importância de fornecedores distantes para este segmento. Um dos exemplos é o caso dos supermercados ingleses que possuem fornecimento diário de legumes e verduras vindas do Quênia por avião (DOLAN; HUMPHREY, 2000). Estes fatos fazem com que segmentos produtivos por todo o mundo sofram as consequências dessa estratégia dos supermercados e, diante da amplitude dessa ação, faz-se fundamental investigar as características das transações entre supermercados e fornecedores de frutas frescas e como se estruturam as cadeias de valor de frutas frescas para exportação para o mercado europeu.

De maneira a atender ao objetivo proposto, o trabalho é dividido em quatro partes, além desta introdução. A 
seção 2 trata da discussão conceitual na qual se discorre sobre as abordagens de cadeia de valor global (CVG) e economia dos custos de transação (ECT). Na seção 3 são apresentados o método e a investigação sobre as cadeias de valor de manga e uva in natura para o mercado europeu. No item 4, é realizada a discussão dos resultados seguida das considerações finais.

\section{Discussão conceitual}

\subsection{Cadeia de Valor Global - CVG e Economia dos Custos de Transação - ECT}

$\mathrm{Na}$ abordagem de cadeia de valor global (CVG), a cadeia de produção é chamada de cadeia de valor, a qual consiste no arranjo das atividades necessárias para produzir um bem ou serviço, desde a sua concepção, passando pelas diferentes fases da produção até a entrega para o consumidor final (KAPLINSKY; MORRIS, 2001). O termo valor significa que, a cada etapa do processo, é adicionado valor ao produto.

$\mathrm{O}$ foco geral da abordagem refere-se às atividades desempenhadas pelos agentes de uma determinada cadeia produtiva global e às suas interações. A ideia de globalização vem do fato de que os fluxos entre os países estão cada vez mais intensos com o crescimento da importância da industrialização orientada para o crescimento das exportações. Nesse contexto, agentes de diferentes países estão cada dia mais relacionados e o que se vê são atividades como a produção de um determinado bem e sua colocação no mercado - tais como: produção e marketing - serem desenvolvidas em diferentes países. A noção de global nos remete à ideia da interação entre agentes localizados em diferentes países, o que nos leva a pensar que os agentes de países em desenvolvimento estão inseridos em um certo ambiente com uma série de condicionantes, enquanto os agentes internacionais estão sujeitos a um outro ambiente com outros condicionantes. Vale lembrar que também há diferentes instituições nos diferentes ambientes e, no que se refere às instituições, a abordagem tem como principal preocupação o estudo das consequências do comportamento delas para os agentes envolvidos.

Nesta literatura, grande destaque é dado ao conceito de governança. Ao se falar de relacionamentos na cadeia de valor, faz-se necessário tratar o conceito de governança que tem como foco justamente as relações de poder entre os segmentos de uma cadeia produtiva em suas interações com mercados globais. Basicamente, é quando a atividade econômica não é gerenciada pelas forças de mercado (HUMPHREY; SCHMITZ, 2004). Algumas evidências empíricas mostram que um determinado ator econômico de qualquer elo da cadeia (segmento) pode determinar certos padrões de qualidade que influenciam diretamente na configuração das cadeias produtivas no que diz respeito a sua estrutura e relações entre os agentes de diferentes segmentos. A essa ação dá-se o nome de governança, que pode ser do tipo producer-driven e buyer-driven. $\mathrm{O}$ primeiro caso é quando os agentes produtores ditam as regras para os outros agentes ao longo da cadeia, como é o caso das montadoras de veículos no Brasil (GEREFFI, 1999). Já quando o comprador exerce um certo controle sobre a cadeia, coordenando suas atividades, dá-se o nome de buyer-driven. Segundo Dolan e Humphrey (2000), são os varejistas ingleses que determinam certas regras de comercialização para a cadeia de vegetais frescos na África e que definem o número de fornecedores, seus sistemas de qualidade e procedimentos para monitorar a performance.

Alguns autores (RAIKES; FRIIS; PONTE, 2000) apontam que o conceito de governança apresentado nessa abordagem é bastante estático. Ou seja, as definições de producer-driven e buyer-driven poderiam ter gradações, tendo em vista que uma cadeia produtiva compreende vários agentes, países e, portanto, ambientes que podem ser bastante distintos, o que poderia implicar diferentes níveis e tipos de governança.

Um dos fatores fundamentais para o surgimento da governança em uma cadeia de valor (ou novos tipos de relacionamento, que não sejam relações de mercado) é o fato de determinados agentes precisarem ter maior controle sobre as atividades da cadeia de valor em função de especificações de produtos, processos, bem como o nível de perdas caso o fornecedor não atenda aos padrões demandados (HUMPHREY; SCHMITZ, 2004). Além disso, os diferentes níveis de governança poderiam ser explicados a partir de dois extremos: relações de mercado e hierarquia (ou integração vertical). A primeira revela a total ausência de controle por parte dos agentes (que não seria considerada uma estrutura de governança sob o enfoque da abordagem de CVG), enquanto a integração vertical é quando a firma internaliza as atividades, ou seja, tem o total controle. Neste ponto, é utilizada a abordagem de economia dos custos de transação para caracterizar as relações entre os diferentes agentes envolvidos nas cadeias de valor de exportação de manga e uva para o mercado europeu.

A economia dos custos de transação é uma abordagem microanalítica que tem como foco a investigação das características da transação que irão nortear a adoção do mecanismo de comercialização, que minimiza os custos de transação envolvidos.

Os pressupostos da ECT são racionalidade limitada e possibilidade de comportamento oportunista dos agentes envolvidos na transação. Ao se realizar uma determinada transação, os agentes não têm todas as informações a respeito e possuem racionalidade limitada para analisar todas as situações que poderiam ser desencadeadas por aquela relação contratual. Além disso, os agentes que, por exemplo, detiverem alguma informação privilegiada (informação assimétrica) a respeito da transação, podem 
usá-la de maneira oportunista no futuro. Sendo assim, problemas deste tipo podem elevar os custos de transação envolvidos que, segundo Williamson (1985), são

\footnotetext{
"os custos ex-ante de preparar, negociar e salvaguardar um acordo, bem como os custos ex-post dos ajustamentos e adaptações que resultam quando a execução de um contrato é afetada por falhas, erros, omissões e alterações inesperadas. Em suma, são os custos de conduzir o sistema econômico"
}

Ainda, segundo Williamson (1985), os custos de transação podem ser divididos em custos de informação, de negociação e de monitoramento (enforcement).

Os atributos das transações são: especificidade de ativos, frequência e incerteza. A partir dos estudos feitos por Williamson, pode-se observar um grande enfoque sobre a dimensão especificidade de ativos. É importante ressaltar que a especificidade de ativos é resultante de um investimento específico àquela transação. Caso a transação não ocorra, o investimento realizado não pode ser alocado em uma outra transação, sem que haja perdas. Sendo assim, quando há um aumento da especificidade do ativo envolvido na transação, existe a tendência em se adotar estruturas de governança que tenham maior controle sobre a transação para minimizar os custos de transação envolvidos, cresce, pois, a tendência à adoção da integração vertical. Ou seja, internalizam-se as atividades. Além disso, quando existe uma frequência maior de transações, a tendência é que haja uma diminuição da incerteza naquela transação, pois os agentes envolvidos se conhecem melhor e podem desenvolver uma certa relação de confiança, o que minimizaria o comportamento oportunista e diminuiria os custos de transação envolvidos. No caso da terceira dimensão da transação, a incerteza, o aumento desta envolve o crescimento dos custos de transação envolvidos, pois os agentes irão dispender mais recursos para estabelecer mais salvaguardas contratuais e para monitorar a transação ex-post (enforcement). Já as estruturas de governança que se encontram entre a estrutura de mercado e a integração vertical, as chamadas formas híbridas de governança, podem ser encontradas em formas variadas, tais como redes de firmas, contratos de longo prazo, franquias, parcerias, dentre outras (MENARD, 2002).

Dependendo da magnitude da especificidade do ativo exigido nessa transação, os agentes econômicos irão escolher a estrutura de governança que proporcione $o$ menor custo de transação. Quanto maior a especificidade do ativo envolvido na transação, maior a necessidade de controle, maior a tendência à adoção da integração vertical como estrutura de governança (ZYLBERSZTAJN, 1995). Segundo Williamson (1991), a especificidade de ativos pode se caracterizar por seis formas distintas. São elas:
1) especificidade locacional: está diretamente relacionada ao transporte e armazenagem de produtos que são específicos de uma certa transação;

2) especificidade de ativos físicos e (3) humanos: diz respeito aos ativos físicos e aos recursos humanos que foram investidos para realizar determinada transação e que não podem ser reaproveitados, sem perdas de valor, em um outro tipo de transação.

4) especificidade de ativos dedicados: são os ativos investidos numa transação com um agente particular;

5) especificidade de marca: especificidade relacionada aos investimentos na marca de uma empresa, que compreende aspectos como reputação, confiabilidade do consumidor na marca de uma determinada empresa;

6) especificidade temporal: "é quando o valor da transação depende sobretudo do tempo em que ela se processa" (FARINA; AZEVEDO; SAES, 1997, p. 87). Extremamente relevante para produtos perecíveis, que vão perdendo seu valor ao longo do tempo e cuja transação deve ser feita rapidamente.

A abordagem de economia dos custos de transação é utilizada neste trabalho para caracterizar as transações entre supermercados e fornecedores de frutas frescas. Este trabalho não é a primeira experiência em que os conceitos de ECT são incorporados à análise de CVG para analisar as características das transações entre os agentes de uma cadeia de valor global (HUMPHREY, 2005; HUMPHREY, SCHMITZ, 2004). Vale lembrar que as abordagens se complementam apesar do conceito de governança ser distinto. Enquanto CVG destaca a questão da governança tendo em vista o poder indutor de determinados agentes na cadeia produtiva, a ECT refere-se à coordenação das atividades e considera o mecanismo de mercado como uma estrutura de governança específica e uma forma de coordenação. Já a CVG considera a forma de mercado como aquela em que não haveria governança nenhuma, ou seja, nenhum agente que compõe a cadeia produtiva estaria interessado em induzir qualquer atividade ou um novo padrão para os outros segmentos ao longo da cadeia produtiva.

\section{As cadeias de valor de manga e uva in natura para o mercado europeu}

O método escolhido para análise empírica foi o estudo de casos múltiplos. O estudo de caso serve para solucionar questões do tipo "como" e "porquê" dentro de um contexto da vida real (YIN, 1989). Segundo Lazzarini (1997), o estudo de caso tem como vantagem o fato de focar a questão da interpretação dos dados, que é o objetivo deste trabalho, e não sua mensuração.

As críticas ao método escolhido estão relacionadas à possibilidade de haver problemas na replicação da pesquisa científica e à generalização dos resultados. No entanto, o 
objetivo do método é proporcionar generalizações teóricas e isto pode ser beneficiado com a realização de mais de um caso (EASTERBY-SMITH et al., 2002; VOSS et al., 2002). Segundo Eisenhardt (1989) e Malhotra (2001), é fundamental que os estudos de caso sejam realizados de maneira estruturada, de modo a ter um processo replicável.

Neste trabalho foram investigadas duas cadeias produtivas, a de manga e a de uva, voltadas para o mercado europeu. Segundo o Relatório da Food and Agricultural Organization (FAO, 2007), sobre frutas tropicais, a manga é a fruta dominante neste grupo compreendendo $36 \%$ da produção mundial de frutas tropicais. A América Latina é responsável por $17 \%$ da produção mundial de manga e o Brasil é o terceiro maior exportador mundial de manga (FAO, 2007). Praticamente $100 \%$ da manga e da uva exportadas pelo Brasil têm origem na região do Vale do São Francisco. Em termos de destino, a União Europeia é o maior destino das exportações brasileiras de manga e uva, $90 \%$ e $68 \%$, respectivamente (SECEX, 2005).

Foram realizadas entrevistas presenciais, por meio de questionários semiestruturados, nos anos de 2004 e 2005, com 11 importadores de manga e uva localizados na Alemanha, Holanda e Reino Unido, bem como com atacadistas ingleses localizados em um dos maiores mercados de produtos frescos de Londres, o Spitafields (CADILHON et al., 2003). No Vale do São Francisco, foram realizadas entrevistas com 4 pequenos e médios produtores de manga e uva de 8 empresas produtoras e exportadoras que pertencem ao Projeto Produção Integrada - PIF, implantada pela Companhia de Desenvolvimento do Vale do São Francisco - Codevasf, e pelo Serviço de Apoio a pequenas e médias empresas - SEBRAE. Além disso, foram entrevistados o presidente da Valexport, a maior associação de exportadores do Vale, três presidentes de cooperativas e representantes do Sebrae, Codevasf e Embrapa Semi-Árido.

De maneira geral, pode-se dizer que as cadeias de manga e uva in natura para exportação são constituídas por fornecedores de insumos, produtores, agentes intermediários (ou importadores), distribuidores (atacadistas/varejistas/ indústria de catering) e consumidor final. Na seção 3, são identificadas as características das cadeias de valor de manga e de uva no Vale do São Francisco destinadas ao mercado europeu.

\subsection{Características da produção de uva e manga no Vale do São Francisco}

A região do Vale do São Francisco, mais especificamente o submédio São Francisco, oferece condições propícias para a atividade agrícola irrigável, o que a configura uma das maiores regiões exportadoras de frutas frescas no Brasil. A área irrigada, com predominância de frutas nessa região, estende-se por 120 mil hectares e, dentre as principais atividades agrícolas, ressaltam-se as culturas da manga e da uva. Na produção de uva e manga destaca-se, no Vale, o polo agroindustrial de Petrolina-Juazeiro (Bahia e Pernambuco), onde são encontrados os maiores produtores de manga e uva do País e, praticamente, $100 \%$ do total de manga e uva exportado pelo Brasil sai desta região. Em 2004, a participação do Vale do São Francisco nas exportações brasileiras de manga foi de $92 \%$ e de uva $98 \%$ (VALEXPORT, 2005).

\subsubsection{A produção de uva}

O Brasil é o décimo terceiro maior produtor e exportador de uva com uma produção de 1.208.680 toneladas. Os três principais produtores mundiais são Itália, França e Estados Unidos e os três maiores exportadores são Chile, Estados Unidos e Itália (FAO, 2008).

A região de Petrolina-Juazeiro não apresenta grandes oscilações climáticas, fato que possibilita duas safras de uva por ano, o que é inédito dentre os países produtores. A primeira safra de uva ocorre no primeiro semestre, nos meses de maio, junho e julho, e a segunda ocorre no segundo semestre, nos meses de outubro, novembro e dezembro. Segundo pesquisa empírica realizada com produtores de uva da região, na primeira safra de uva, no primeiro semestre, a produção é mais baixa se comparada com a segunda safra. Nesse período do ano, as temperaturas são mais amenas, o que não favorece a produtividade dos parreirais e, além disso, os preços da uva no mercado europeu são inferiores, se comparados aos do segundo semestre. Sendo assim, o produtor programa a produção de um maior volume de uva para o segundo semestre. Para isso, os produtores da região fazem um planejamento de produção, o que o produtor chama de escalonamento, para programar a utilização das câmaras-frias e da mão de obra, de forma a não haver carência destes recursos. Além disso, os produtores usam técnicas de indução floral para programar quanto e quando produzir determinadas variedades de maneira a atender mercados específicos. Os parreirais são submetidos à poda e entram em estado de dormência (quase mortas). Quando se quer produção, trata-se a planta quimicamente, o que suspende o estado de dormência e faz com que a floração tenha início. Os produtores assinalam que, com este processo de planejamento (escalonamento) e devido às condições climáticas da região, é possível produzir uva o ano todo. A produção de uva é mais tecnificada e sua manutenção é mais cara, se comparada com a da manga. Segundo dados da Embrapa (2005), o custo total de implantação e manutenção de um hectare de uva no submédio São Francisco é de $\mathrm{R}$ \$ 53.121,00 reais nos primeiros três anos.

A partir do momento em que a uva é colhida, o processo de amadurecimento é finalizado. Sendo assim, a quantidade de açúcar (ou brix) que a fruta tem, quando colhida, será mantida. O brix para mercado externo tem que ser de, no mínimo, 14. No entanto, na prática, os supermercados na Europa vendem uvas com o brix variando de $16 \%$ a $20 \%$. 
A uva brasileira apresenta brix alto, devido à quantidade de sol a que as frutas são submetidas no parreiral.

De maneira geral, o produtor brasileiro de uva procura focar suas exportações para o mercado inglês, que é mais exigente, paga melhores preços e apenas consome uva da variedade verde e sem semente, com predominância da variedade chamada Festival. De forma geral, a principal exigência do mercado europeu para importação de uva está relacionada à quantidade de resíduos. Nesse aspecto, os produtores apontam a importância do sistema de Produção Integrada de Frutas, que proporciona a sistematização do processo produtivo e o registro de todas as atividades e produtos utilizados no tratamento e manejo do parreiral. Em segundo lugar, vêm os certificados, entre os quais se destacam o EurepGap, o British Retail Consortium e alguns certificados próprios de determinadas redes varejistas como o Nature's Choice da rede varejista da Inglaterra Tesco e Marks and Spencer - M\&S, que criou seu próprio padrão de qualidade que leva o nome de Field-to-Fork.

Segundo dados da Freshinfo (2004), o fornecimento brasileiro de uva no mercado europeu ocorre do final do mês de abril até o mês de junho, e do mês de setembro ao mês de janeiro. Os principais países concorrentes do Brasil no mercado europeu são África do Sul, Argentina, Chile e Itália. A uva brasileira apenas obtém preços favoráveis no continente europeu quando os países da União Europeia, tais como Itália e Grécia, cessam seu fornecimento. O Chile fornece para o mercado europeu do mês de janeiro ao mês de julho, tornando a fornecer algumas variedades nos meses de novembro e dezembro. Segundo alguns produtores entrevistados na pesquisa de campo, o Brasil está praticamente sozinho no mercado europeu do mês de outubro ao mês de dezembro, que é o período de melhores preços do ano no continente europeu.

Quanto às preferências, os mercados consumidores da Inglaterra e dos países nórdicos estão mais atentos à praticidade do que ao sabor, por isso há preferência por uva sem semente que, segundo especialistas no assunto, têm um sabor inferior se comparado à variedade de uva moscato, que tem cor escura e semente grande. Essa última é a preferência dos países do continente, como a Espanha, por exemplo.

\subsubsection{A produção de manga}

O Brasil é o oitavo maior produtor de manga com uma produção de 850 mil toneladas e o terceiro maior exportador com um volume de 111.181 mil toneladas. Os três principais produtores mundiais são Índia, China e Tailândia e os dois maiores exportadores são México e Índia (FAO, 2008).

A região de Petrolina-Juzeiro pode produzir manga o ano todo em função de suas condições climáticas favoráveis, irrigação e manejo adequado do pomar, com o uso de técnicas de floração. Esse fato faz com que o Brasil tenha um longo período de fornecimento ao continente europeu, que vai de agosto a novembro. A variedade de manga que predomina no polo Petrolina-Juazeiro é a Tommy Atkins, seguida das variedades Kent, Keitt e Hadden. A primeira variedade predomina nas vendas para o mercado externo devido a sua alta produtividade no polo Petrolina-Juazeiro e devido ao fato de manter suas propriedades por um período mais longo de tempo, o que é fundamental tendo em vista a longa distância até o mercado consumidor.

A mangueira é uma árvore bastante tradicional nos pomares brasileiros e é de fácil manuseio, o que possibilita seu cultivo facilmente. Segundo a Embrapa (2005), o cultivo da mangueira no Brasil pode ser dividido em duas fases. A primeira é caracterizada pelo plantio extensivo de variedades locais tais como Bourbon, Espada e Rosa, com pouco ou nenhum uso de tecnologias. A segunda fase é caracterizada pelo elevado nível tecnológico, pela irrigação, indução floral, cultivo de variedades melhoradas e de aceitação no mercado externo, como Tommy Atkins, Kent, Keitt. Em se tratando do cultivo, a árvore da manga demora cerca de quatro anos para chegar à produção. No quarto ano, a planta começa a produzir e, no sexto ano, atinge produção plena. Segundo a Embrapa (2005), os custos totais para implantação e manutenção de 1 hectare de manga no submédio São Francisco, nos seis primeiros anos, são por volta de $\mathrm{R} \$ 25.357,00$ reais.

A manga, mesmo após a colheita, continua o processo de maturação. Em função disso, a manga é uma fruta altamente perecível que precisa ser comercializada rapidamente para não perder valor. Segundo os produtores do polo, a manga deve chegar ao cliente final entre vinte e vinte e nove dias. Dentro desse período, devem-se contar três dias para a colheita, um dia para processamento no galpão de embalamento, um dia para transporte do galpão para o porto de origem, um dia de espera no porto para ser embarcada e doze dias de transporte marítimo, o que deixaria cerca de sete dias para viabilizar sua comercialização. Para tentar minimizar esse problema, as mangas são colhidas num processo de maturação bastante inicial. Os níveis de maturação da manga variam de um a cinco, em ordem crescente de maturação, e a manga destinada para o mercado externo é colhida no nível dois. No caso da fruta ser vendida rapidamente no mercado internacional e não estar no estágio de maturação ideal para ser colocada no ponto de venda, ela é tratada com etileno para acelerar o amadurecimento.

A manga é uma fruta considerada exótica na Europa e, como os próprios produtores do polo Petrolina-Juazeiro ressaltam, o mercado europeu de manga é novo, começou a ser explorado na década de 90 . Em compensação, uma das vantagens do Brasil, segundo a pesquisa de campo, é que o país produz durante um longo período e em grandes quantidades, principalmente da variedade Tomy Atkins, o que lhe confere uma vantagem importante em relação aos 
concorrentes. No mercado europeu as principais exigências para manga e uva estão relacionadas à quantidade de resíduos e aos certificados. Os mesmos certificados aplicados para uva no mercado europeu aplicam-se à manga. Os principais competidores brasileiros no mercado europeu de manga são Peru, Equador, África do Sul, Costa Rica e Porto Rico. Este último é um dos principais concorrentes do Brasil no mercado inglês e produz apenas as variedades Kent e Keitt, aquelas de que o varejo inglês vem aumentando as compras.

\subsection{Os distribuidores e os agentes intermediários}

Pode-se observar que as vendas de manga e uva na Europa são divididas entre varejistas, atacadistas e indústria de catering. Esta última é responsável por abastecer o mercado institucional. $\mathrm{O}$ destino principal da manga e da uva brasileira in natura são os supermercados na Europa, seguidos do atacado e da indústria de catering, que tem uma participação pequena nas compras de frutas. As diferenças entre eles podem ser agrupadas em função do volume demandado e dos padrões de qualidade exigidos. É consenso entre os fornecedores que o setor varejista é o mais exigente, em termos de padrão de qualidade e demanda por grandes volumes. Também questões como confiabilidade de entrega e capacidade de inovação são demandadas pelos varejistas. A exceção volta-se às vendas de uva na Alemanha, onde o atacado vende uvas com maior qualidade e preço superior, comparado com o varejo.

Essas exigências podem ser agrupadas em exigências ao produtor e ao agente intermediário. Em se tratando do produtor, podem-se observar exigências relativas ao sistema de produção utilizado, que deve ser autossustentável; às técnicas de manejo, que permitam o registro e controle no uso dos agroquímicos utilizados no cultivo; à confiabilidade de entrega; à capacidade técnica para o desenvolvimento de novas variedades; e para o melhoramento de determinadas características do produto referentes à aparência.

Já os agentes intermediários são instados a assumir determinadas atividades nas cadeias produtivas de manga e uva que, anteriormente, eram dos supermercados. Dentre as atividades podem ser ressaltadas: embalagem, transporte, etiqueta no produto, promoções dentro do supermercado, responsabilidade pelo sortimento do produto e por fornecer o chamado "enxoval", que é o fornecimento de um primeiro lote de produtos de graça na abertura de uma nova loja do supermercado. Além disso, em algumas situações, os fornecedores assumem o gerenciamento da categoria de produtos do supermercado e colocam promotores junto às gôndolas para alavancar as vendas.

Os supermercados têm como estratégia manter relações próximas com os fornecedores, o que lhes permite a realização de contratos de produção e o gerenciamento da cadeia de fornecimento, sem incorrer nos custos de produção do bem propriamente dito e os riscos da atividade agrícola. Além disso, os supermercados definem e controlam os preços e garantem uma certa flexibilidade, que seria comprometida no caso de uma integração vertical. Em se tratando dos preços, os supermercados pagam preços superiores, quando comparados com aqueles pagos pelos atacadistas, mas, segundo alguns fornecedores, em função das exigências demandadas pelos supermercados e das atividades que lhes são repassadas, há situações em que os preços pagos por atacado e varejo se equiparam, principalmente na Inglaterra. No entanto, ainda nessa situação, a principal vantagem do varejo continua sendo a garantia da compra em grandes volumes.

Também há exigências relativas às características do produto. No caso da uva, a variedade de uva brasileira sem semente mais demandada na Europa é a Festival, que tem cor verde e não tem semente. De acordo com agentes intermediários e alguns atacadistas, apesar de a uva brasileira ter o brix de acordo com as exigências do mercado inglês, ela é mais amarelada e isso atrapalha as vendas, pois o consumidor inglês tem preferência por uva verde. Sendo assim, vem sendo solicitado ao produtor brasileiro que use técnicas de cultivo que diminuam a aparência amarelada da uva. Além disso, o mercado inglês apenas consome uva das variedades sem semente.

Pode-se observar que há diferenças entre as preferências dos mercados consumidores dos países europeus, destacando-se a Inglaterra e Alemanha e as estruturas do segmento varejista de cada um destes países. Na Inglaterra, os supermercados são mais exigentes, incluindo em suas exigências certificados de qualidade públicos e privados. Já na Alemanha, que segue um modelo diferente de varejo, baseado nas lojas de desconto (discount groceries), há um certo padrão de qualidade e os certificados públicos também são exigidos, mas há uma preocupação maior com menores preços. Por exemplo, as uvas de maior qualidade são encontradas nas pequenas lojas de bairro também chamadas de varejos tradicionais, que vendem frutas com maior qualidade e com maior preço do que os supermercados alemães. Na Inglaterra as redes de supermercados são responsáveis por cerca de $76 \%$ das vendas de produtos frescos (DOLAN e HUMPHREY, 2000), o que faz com que os atacadistas tenham pouca participação nas compras de manga e uva vindas do Brasil. Os supermercados têm fornecedores, geralmente exclusivos, chamados de gerenciadores de categoria. $\mathrm{Na}$ Inglaterra pode acontecer desse intermediário ter relações muito próximas com o varejo, ser um gerenciador de categoria, e comprar as frutas de outros agentes intermediários e não diretamente dos fornecedores. Uma segunda alternativa é atuar próximo aos fornecedores e distante dos supermercados, ou seja, não ser gerenciador de categoria. E, por último, atuar próximo dos fornecedores e dos supermercados.

À medida que se aproxima dos supermercados, o agente intermediário é obrigado a adicionar mais valor ao produto, realizar maior número de atividades e torna-se mais especializado, cuidando diretamente da gôndola do supermercado e sendo responsável pelo fornecimento de 
determinada fruta, ou determinado grupo de frutas, durante o ano, para certa rede varejista. Vale lembrar que, no contrato do gerenciador de categoria com a rede varejista, estão especificados: quantidade, variedade, tamanho, país de origem, tempo de fornecimento (geralmente 1 ano), certificados e, algumas vezes, os preços são fixos. Segundo entrevistas realizadas com agentes intermediários, a determinação de preço vai depender da política da rede varejista. No caso do gerenciador de categoria não atuar diretamente com fornecedores, essas especificações do varejo são transferidas para os agentes intermediários, seus fornecedores, que repassam para os produtores (Figura 1).

$\mathrm{Na}$ Inglaterra as grandes redes de supermercado, como Tesco, Sainsburry, Waitrose, dentre outras, têm poucos fornecedores para cada categoria de produtos. No caso de algumas frutas, tais como manga e uva, cada rede tem um ou, às vezes, dois gerenciadores de categoria responsáveis pelo suprimento anual de cada fruta, e esse agente pode apenas fornecer para uma rede varejista. Nas palavras de alguns importadores, quando alguns países fornecedores têm algum problema com o fornecimento de frutas, os gerenciadores de categoria ficam "desesperados" à procura da quantidade de frutas necessária para cumprir os contratos com o varejo e pagam qualquer preço pelo produto. Sendo assim, no caso do Reino Unido, as redes de varejo determinam as regras e padrões de qualidade para a cadeia agroalimentar como um todo, mas mantêm relações próximas apenas com um pequeno grupo de fornecedores, que são intermediários entre as redes e os produtores/ exportadores de frutas de países em desenvolvimento ( $U K$ COMPETITION COMMISSION, 2000) (Figura 2).

\subsection{Agentes intermediários}

De maneira geral, o agente intermediário é responsável por todas as atividades a partir da saída das frutas do porto ou aeroporto de origem, até a venda da fruta para o varejista, atacadista ou para a indústria de catering. As atividades são as seguintes: transporte do país produtor até o país de destino, inspeção dos contêineres na chegada para verificar padrões de qualidade, armazenagem, seleção de acordo com calibre e padrão de qualidade, transporte até o ponto de venda. Ao atuar diretamente com o produtor, os agentes intermediários são responsáveis por todas as atividades, a partir do carregamento das frutas no porto ou aeroporto de origem, e têm uma comissão para realizar seus serviços, que pode variar de 7\% a 10\% (Figura 3).

No caso do Reino Unido, há situações em que os agentes intermediários atuam como gerenciadores de categoria, mantendo relações próximas com os supermercados, mas também desenvolvem a função do importador, como pode ser visto na Figura 3. Ou seja, o gerenciador de categoria está próximo dos supermercados e mantém relações diretas com os fornecedores localizados no Brasil, por exemplo. No caso das uvas para o Reino Unido, há um grande gerenciador de categoria no mercado inglês, chamado GrapesDirect, que fornece para os principais supermercados e que compra a uva diretamente de fornecedores brasileiros. Geralmente, o gerenciador é responsável pela realização de vistorias nos locais de produção e nos galpões de embalamento para verificar se as exigências dos varejistas estão sendo cumpridas. Em outras situações, o varejo tem funcionários que realizam essa vistoria nos períodos de safra. Em entrevista realizada com importadores de manga e uva brasileira no Reino Unido, alguns deles comentaram que algumas redes varejistas criam problemas, quando o "seu" gerenciador de categoria compra frutas de um intermediário que fornece para um gerenciador de categoria de uma outra rede de supermercados.

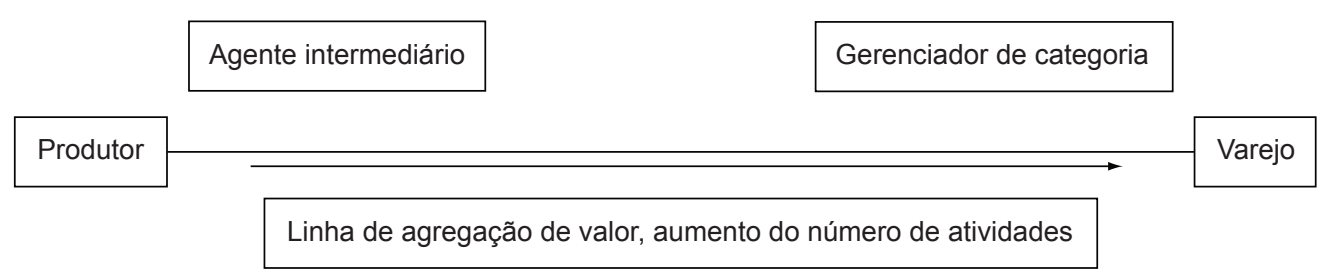

Figura 1. Posicionamento dos agentes produtivos na linha de agregação de valor.

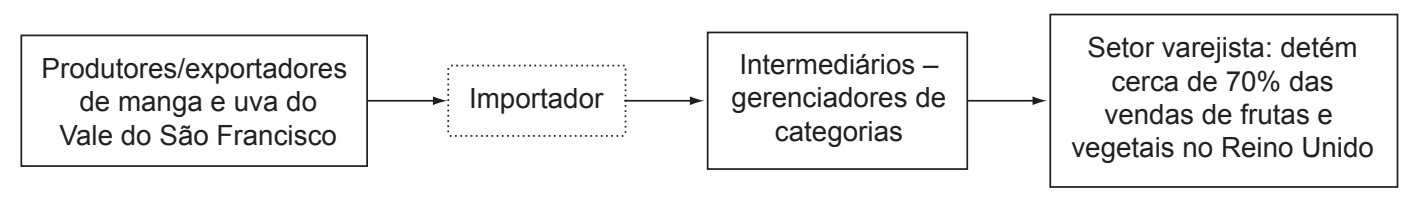

Figura 2. Exportações de manga e uva do Brasil para a Inglaterra - presença do importador. 


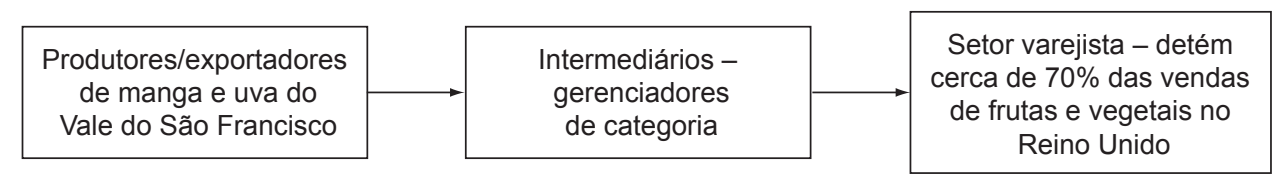

Figura 3. Exportações de manga e uva do Brasil para o Reino Unido.

No caso das exportações brasileiras de manga e uva, há situações em que os produtores vendem diretamente para os gerenciadores de categoria ingleses, como é o caso de algumas grandes empresas produtoras e exportadoras de manga e uva do polo; e há também empresas do polo que comercializam sua produção no mercado externo. Além disso, há situações em que os produtores vendem para agentes intermediários, os quais vendem para os gerenciadores de categoria (verificar figuras 2 e 3 ).

Em toda a Inglaterra há cerca de 7 gerenciadores de categoria. Segundo os gerenciadores, o fato de haver um contrato de fornecimento naquele ano não implica um relacionamento que garanta o contrato para o ano seguinte. Há várias empresas no mercado dispostas a atuar como gerenciadores (Tabela 1).

Segundo um gerenciador de categoria entrevistado: "Não há uma relação de confiança com os supermercados". Já um outro entrevistado acrescentou que o funcionário do varejo, responsável por negociar com os fornecedores, muda constantemente, sendo assim normal que ele não conheça profundamente as atividades do setor, a produção e a situação dos produtores. Segundo o agente intermediário: "Eles não estão preocupados com os produtores!", "Há uma falta de percepção em relação aos produtores!".

No resto do continente, em países como a Alemanha, França e Portugal, pode-se observar que não existe a Figura do gerenciador de categoria e, nessa situação, é possível verificar vários casos de produtores e exportadores brasileiros que vendem diretamente para supermercados alemães e franceses. Nesse contexto, é possível excluir um agente da cadeia, o gerenciador de categoria, e os produtores ficam mais próximos dos distribuidores das

Tabela 1. Algumas redes de varejo e seus gerenciadores de categoria para manga e uva in natura no Reino Unido.

\begin{tabular}{lccc}
\hline \multicolumn{2}{c}{ uva } & \multicolumn{2}{c}{ manga } \\
\hline $\begin{array}{c}\text { Gerenciadores } \\
\text { de categoria }\end{array}$ & Varejo & $\begin{array}{c}\text { Gerenciadores de } \\
\text { categoria }\end{array}$ & Varejo \\
\hline Grapes Direct & Tesco & Utopia & Tesco \\
RedBridge & Sainsbury & Minor, Weir e Willis & Sainsbury \\
Hars e & Morrison e & Malet Select & Marks e \\
Hagebauer & Safeway & & Spencer \\
\hline
\end{tabular}

Fonte: elaborado pelos autores com base em pesquisa de campo (2004, 2005). frutas. No caso da Alemanha, as cinco principais redes de varejo possuem $60 \%$ do market-share. O modelo de varejo de alimentos que predomina na Alemanha é o de loja de descontos (grocery discounters), que é caracterizado pelo baixo nível de serviços, preços baixos e menor variedade de produtos (WORTMANN, 2003, 2004). Um dos elementos que também caracterizam o varejo alemão são as chamadas afiliações, que consistem na integração de atacadistas e varejistas, e a importância do atacado nas vendas de alimentos frescos por meio dos três principais mercados atacadistas do país, os mercados de Hamburgo, Munique e Stuttgart (CADILHON, et al., 2003). Um exemplo de afiliação é a existente entre Edeka e Rewe no varejo de alimentos. Recentemente, o maior grupo varejista do mundo, o Wal Mart, teve dificuldades para adaptar suas atividades ao ambiente alemão, tanto do ponto de vista dos consumidores como no momento de empregar mão de obra nesse país. Estas dificuldades fizeram com que o Wal Mart vendesse suas instalações na Alemanha para o Metro, que é famosa por seu formato de lojas de desconto (The Economist, 2006).

Segundo entrevistas realizadas com agentes intermediários, as redes de varejo apresentam diferentes padrões de exigência, apesar de os certificados serem os mesmos para todas elas, com exceção dos padrões de qualidade particulares determinados por cada varejista. Em primeiro lugar, do mais para o menos exigente, estão Mark\&Spencer e Waitrose no mesmo nível (ambos ingleses); Tesco e Sainsbury; Asda; e, por último, as redes de varejo alemães Aidi e Lidl.

\subsection{Relações dos agentes intermediários com os fornecedores de manga e uva in natura do polo Petrolina-Juazeiro}

Quando os agentes intermediários referem-se às suas compras de frutas, eles mencionam o país fornecedor e não um produtor ou exportador especificamente. Esse fato é importante, pois, caso haja algum problema com o fornecimento, todos os agentes produtores de um determinado país serão atingidos de alguma forma. Pode-se constatar que os principais elementos considerados para selecionar um país fornecedor de manga e uva in natura são preço, qualidade, variedade (mix) e volume.

Tendo por base as entrevistas realizadas com os agentes intermediários, no caso da manga, o que predomina são as relações de consignação. Segundo os agentes intermediários, 
apesar do Brasil ter uma safra longa e produzir a variedade Tommy Atkins em grandes volumes, a manga ainda é pouco conhecida na Europa e considerada uma fruta exótica, fazendo-se necessária a difusão do consumo nesse mercado. Além disso, a atuação dos produtores brasileiros não é muito planejada. Sendo assim, no segundo semestre do ano de 2004, chegou ao porto de Roterdã um grande volume de manga do Brasil, o que inundou o mercado europeu e fez com que os preços despencassem durante um determinado período. Países como o Peru já realizaram este procedimento no passado e agora têm uma atuação mais planejada na Europa, tendo em vista não causar a queda de preços.

A manga é uma fruta considerada exótica na Europa, principalmente no Reino Unido. Com o objetivo de expandir o mercado consumidor de manga no Reino Unido, foi criada, em 2002, a The Mango Association, que é constituída por produtores, cooperativas de distribuição, importadores e distribuidores engajados no fornecimento e marketing da manga nesse país. Atualmente, a associação vem realizando campanhas em revistas e jornais com o objetivo de "educar" os consumidores britânicos sobre o sabor, uso e versatilidade da manga. De acordo com o presidente da Associação, a manga é uma fruta exótica e apenas consumida pela parcela da população considerada minoria étnica na Inglaterra (ABRAMS, 2004; The mango Association, 2005). Já no caso da uva, o tipo de relacionamento predominante é a consignação com um certo adiantamento de preços. Segundo os agentes intermediários, a uva é uma fruta de mercado consolidado na Europa, e o Brasil apresenta a vantagem de produzir duas safras por ano.

Por sua vez, o relacionamento com preço fixo apenas ocorre quando há escassez da fruta no mercado. No passado, a uva era apenas comercializada a preço fixo, mas esse relacionamento veio mudando ao longo dos anos até chegar à consignação com algum tipo de adiantamento, que é o que ocorre atualmente.

Nas relações entre agentes intermediários e produtores, pode-se observar que os agentes intermediários estão preocupados com as exigências de seu principal comprador, os varejistas. São transferidas informações a respeito dos certificados e quais as mudanças que devem ser feitas para se adequar a elas. Para isso, muitos agentes intermediários têm alguns de seus funcionários presentes no galpão de embalamento, em período de safra, com o objetivo de verificar se os padrões de qualidade são atendidos. Além disso, são transferidas informações a respeito das variedades mais demandadas e os problemas quanto aos padrões de qualidade com que a fruta chega a seu destino. Alguns intermediários destacam a dificuldade em conscientizar os produtores a respeito da importância dos certificados. Eles alegam que, como os certificados não representam aumento das vendas nem preços melhores, há dificuldades para convencer os produtores de sua importância. No entanto, eles ressaltam que, em um futuro próximo, a ausência de certificação pode significar não vender para determinados mercados consumidores.

As Tabelas 2 e 3 mostram um resumo dos pontos fortes e fracos do fornecimento brasileiro de uva e manga na Europa, segundo a pesquisa de campo realizada com agentes intermediários e gerenciadores de categoria na Europa. $\mathrm{O}$ Brasil tem vantagens naturais associadas às duas culturas, manga e uva, e deve aprimorar a questão do planejamento da produção, para não inundar o mercado europeu de manga, bem como aumentar o volume produzido de manga Kent e Keitt. No caso da uva, os agentes intermediários ressaltam a questão do aumento do volume e o aprimoramento das técnicas de manejo e produção que viabilizem um fruto menos amarelado e com melhor aparência.

\section{Resultados e discussão}

\subsection{Produtos comercializados}

Do ponto de vista da produção, pode-se afirmar que a manga exige menos manejo e mão de obra do que o cultivo da uva. O cultivo de uva exige uma série de cuidados durante o processo, tais como poda, técnicas de floração e de desbaste do cacho de uva para atender exigências dos mercados externos por cachos menores. Além disso, enquanto o custo total de implantação e manutenção de um hectare

Tabela 2. Pontos fortes e fracos do fornecimento brasileiro de uva in natura segundo os agentes intermediários europeus.

\begin{tabular}{|c|c|}
\hline \multicolumn{2}{|r|}{ Uva } \\
\hline Pontos Fortes & Pontos Fracos \\
\hline \multirow[t]{4}{*}{ Duas safras por ano } & Pequeno volume produzido \\
\hline & Uva muito amarela para o mercado inglês \\
\hline & $\begin{array}{l}\text { Dificuldades de adaptação de } \\
\text { certas variedades levando } \\
\text { problemas com aparência }\end{array}$ \\
\hline & $\begin{array}{l}\text { Melhorar a questão da } \\
\text { quantidade de resíduos }\end{array}$ \\
\hline
\end{tabular}

Fonte: elaborado pelos autores com base em pesquisa de campo (2004, 2005).

Tabela 3. Pontos fortes e fracos do fornecimento brasileiro de manga in natura segundo os agentes intermediários europeus.

\begin{tabular}{ll}
\hline \multicolumn{1}{c}{ Pontos Fortes } & \multicolumn{1}{c}{ Pontos Fracos } \\
\hline Grande quantidade & $\begin{array}{l}\text { Falta de flexibilidade } \\
\text { em se tratando do cultivo } \\
\text { de novas variedades }\end{array}$ \\
Longo período de produção & $\begin{array}{l}\text { Entrada de grandes quantidades } \\
\text { num mesmo momento, o que } \\
\text { diminui os preços }\end{array}$ \\
\hline
\end{tabular}

Fonte: elaborado pelos autores com base em pesquisa de campo (2004, 2005). 
de uva na região do Vale do São Francisco é $\mathrm{R} \$ 53.121,00$ apenas nos primeiros três anos, o custo por hectare plantado de manga nos primeiros seis anos é de $\mathrm{R} \$ 25.357,00$. Posto isso, a uva tem uma maior especificidade de ativos do que a manga no que diz respeito aos investimentos envolvidos para a realização da atividade. No entanto, a uva apresenta uma menor especificidade temporal quando comparada à manga. A especificidade temporal está principalmente relacionada com a questão da perecibilidade e a uva pode ser mantida por meses em câmaras frias enquanto a manga é altamente perecível e deve ser comercializada dentro de uma semana, pois seu processo de amadurecimento continua depois da colheita.

A especificidade de ativos tem impacto direto na estrutura de governança escolhida para as vendas de manga e uva para o mercado europeu. No caso da manga cuja especificidade dos investimentos feitos na produção é baixa, predomina a consignação que pode ser caracterizada como uma estrutura híbrida de governança. Neste caso, os agentes intermediários prestam o serviço de comercialização das frutas para os produtores brasileiros e ganham uma comissão que varia de $7 \%$ a $10 \%$. Nesta estrutura pode ocorrer das partes realizarem a mesma transação por vários anos, apesar de não haver nenhum compromisso neste sentido, e o produtor assumir qualquer flutuação de preço durante o período da comercialização.

Do ponto de vista do agente intermediário, a transação com o fornecedor de manga não exige muitos investimentos já que há muitos países produtores e fornecedores e, como a fruta ainda é considerada exótica, o consumidor europeu não exige altos níveis de qualidade, o que implica em um menor nível de exigência dos agentes intermediários para seus fornecedores de manga. Além disso, os agentes intermediários são, na maior parte das vezes, responsáveis por todas as atividades a partir do carregamento das frutas no porto de origem, o que mostra que estes detêm todas as informações a respeito do transporte e isto pode ser feito para frutas de diversos países.

No caso da uva, a especificidade de ativos é superior, pois seu cultivo exige maiores investimentos e que são específicos para este tipo de fruta. Neste caso, observa-se que a estrutura de governança da transação entre agentes intermediários e produtores é híbrida. Diferentemente da manga, a transação é de consignação com adiantamento do pagamento. Nesta situação, as partes se relacionam há vários anos (cerca de 10 anos em alguns casos) e, apesar da comissão que os produtores devem pagar aos intermediários no início da safra, os agentes intermediários fornecem um adiantamento no pagamento que é inferior a 50\% do total a ser recebido no final da colheita (Tabela 4).

\subsection{Segmento de distribuição}

Do ponto de vista das características dos distribuidores, pode-se observar que tanto o mercado inglês quanto o alemão caracterizam-se pelo pequeno número de grandes redes de supermercado atuando nas vendas de alimentos. No entanto, as estratégias são distintas. Enquanto os supermercados ingleses possuem fornecedores selecionados (os chamados gerenciadores de categoria) e estruturas de governança híbridas nas transações com fornecedores, as redes alemãs compram manga e uva via mercado, seja por meio de agentes intermediários ou diretamente de fornecedores brasileiros. Também pode ser observada a importância dos grandes mercados atacadistas da Alemanha nas vendas de produtos frescos e como fornecedores de supermercados nesse país, o que não ocorre na Inglaterra.

\subsection{Mercado consumidor}

Do ponto de vista do mercado consumidor, vários autores e agentes do setor de frutas na Inglaterra apontam a importância da praticidade e da conveniência para os consumidores ingleses o que vai ao encontro dos serviços oferecidos pelos supermercados. Já na Alemanha, ainda são muito populares os chamados varejistas tradicionais que podem ser caracterizados, neste caso, como lojas de bairro que vendem produtos frescos. Além disso, os supermercados alemães estão mais focados em preços baixos do que em produtos de qualidade. Enquanto os supermercados ingleses têm grande foco na qualidade e os preços são superiores.

De maneira geral, pode-se afirmar que a estrutura da cadeia produtiva, no caso da Alemanha, apresenta menos agentes e os varejistas alemães não têm fornecedores exclusivos. A estrutura de governança predominante na compra de frutas é o mercado. No caso da uva, predominam as relações de consignação com adiantamento do pagamento e esta fruta tem uma maior especificidade envolvida em função dos investimentos necessários para seu cultivo.

Já o mercado inglês apresenta um segmento varejista extremamente concentrado, com fornecedores exclusivos o que implica em mais agentes na cadeia produtiva e determina que as vendas brasileiras de manga e uva para a Inglaterra tenham que passar, obrigatoriamente, por um gerenciador

Tabela 4. Especificidade de ativos nas transações para compra de manga e uva.

\begin{tabular}{lc}
\hline \multicolumn{1}{c}{ Manga } & Uva \\
\hline $\begin{array}{l}\text { Baixa especificidade de } \\
\text { ativos físicos: baixos } \\
\text { investimentos no processo } \\
\text { produtivo }\end{array}$ & $\begin{array}{c}\text { Alta especificidade de ativos } \\
\text { físicos: altos investimentos no } \\
\text { processo produtivo }\end{array}$ \\
$\begin{array}{l}\text { Alta especificidade temporal: } \\
\text { - o produto deve ser }\end{array}$ & $\begin{array}{c}\text { Baixa especificidade temporal: } \\
\text { comercializado dentro de } \\
\text { uma semana }\end{array}$ \\
$\begin{array}{l}\text { - o processo de maturação } \\
\text { continua após a colheita da da }\end{array}$ & $\begin{array}{c}\text { o processo de matidade desde } \\
\text { fruta }\end{array}$ \\
\hline
\end{tabular}

Fonte: elaborado pelos autores. 
de categoria. Além disso, pode-se observar na Alemanha a presença marcante dos atacadistas na comercialização de manga e uva e a importância dos varejistas tradicionais, localizados nos bairros, vendendo frutas de maior qualidade do que os supermercados que seguem o modelo de lojas de desconto.

\section{Considerações finais}

O objetivo deste trabalho foi caracterizar as transações entre produtores brasileiros de manga e uva e compradores europeus e as estruturas das cadeias de valor de manga e uva para exportação. A pesquisa foi conduzida com a utilização do método de estudo de casos múltiplos, por meio de entrevistas presenciais com questionários semiestruturados.

$\mathrm{O}$ estudo apresentado mostra que as estruturas das cadeias produtivas de manga e uva são distintas quando se compara o mercado inglês com o alemão. Corroborando a teoria, as estruturas de governança são escolhidas em função das dimensões das transações: especificidade de ativos, frequência e incerteza. A uva possui uma maior especificidade de ativos do ponto de vista do seu cultivo e dos investimentos necessários, se comparada com a manga, o que exige a adoção de estruturas de governança que forneçam maior controle para as partes em questão. Sendo assim, a estrutura de governança predominante no caso da uva é a consignação com adiantamento de pagamento.

Tanto na Inglaterra quanto na Alemanha existe uma alta concentração das vendas dos supermercados, mas enquanto na Inglaterra predominam estruturas de governança híbridas nas transações entre agentes intermediários e produtores (e/ou supermercados e produtores), na Alemanha predomina a estrutura de governança de mercado. Os supermercados ingleses têm maior controle em suas transações para compra de manga e uva que os supermercados alemães.

Do ponto de vista das limitações pode-se apontar a ausência de generalização estatística que não é proporcionada pelo método qualitativo utilizado. Esta limitação leva a uma agenda de pesquisa como a realização de pesquisa quantitativa com o objetivo de quantificar as dimensões da transação e o impacto destas sobre a estrutura das cadeias produtivas em questão. Além disso, torna-se importante verificar o comportamento de outros mercados, como, por exemplo, o do mercado brasileiro e analisá-lo comparativamente aos mercados inglês e alemão. No caso do mercado brasileiro, há indicações de que houve uma desconcentração do varejo de alimentos associada à expansão de supermercados independentes (quanto ao número de estabelecimentos e participação de mercado) (FARINA; NUNES, 2002).

Por fim, em termos de implicações acadêmicas o estudo identifica os principais elementos envolvidos nas transações entre o segmento varejista e seu fornecedor de produtos frescos e mostra o comportamento de dois mercados que acabam por se comportar de maneira bastante distinta, como são os casos do mercado inglês e do alemão. Esta constatação abre caminho para novos estudos a respeito da ação dos supermercados sobre as atividades da cadeia de valor e, principalmente, no que diz respeito à inserção de produtores no mercado global. Em termos de implicações gerenciais o estudo mostra a importância em se entender a estrutura da cadeia de valor para cada mercado alvo de maneira a fazer com que os produtores possam negociar sua inserção no mercado externo obtendo maior vantagem competitiva.

\title{
The transactions between European supermarkets and Brazilian fresh fruit producers
}

\begin{abstract}
The aim of this paper is to investigate the transactions between European supermarkets and Brazilian fresh fruit producers and the structure of the Brazilian mango and grape value chain to Europe. The element pointed out in this paper is the characteristic of the distributor segment. There are indications that the structures of the retail sector affect the strategies of developing countries producers in global markets. In addition, the procurement strategies of the retail sector are different when compare the United Kingdom and Germany. The Global Value Chain and Transaction Costs Economy approaches were used as theoretical background. The method selected for this study was the multiple case studies which were made viable by means of semi-structured questionnaires conducted with mango and grape producer's agents in Brazil and with mango and grape imported agents located in the United Kingdom and Germany.
\end{abstract}

Keywords: Fresh fruit supplier's supermarket transaction. 
ABRAMS plea for mango to retain exotic appeal. Fresh Produce Journal, 03 de setembro de 2004.

ASSOCIAÇÃO DOS PRODUTORES EXPORTADORES DE HORTIGRANJEIROS E DERIVADOS DO VALE DO SÃO FRANCISCO - VALEXPORT. Potencial Frutícola do Vale do São Francisco: Apresentação. Petrolina, 2005.

CADILHON, J. J. et al. Wholesale markets and food distribution in Europe: new estrategias for old functions. London: Centre for Food Chain Research, Department of Agricultural Sciences, Imperial College London, 2003. (Discussion Paper, n. 2).

DOLAN, C.; HUMPHREY, J. Governance and trade in fresh vegetables: the impact of UK supermarkets on the African horticulture industry. Journal of Development Studies, v. 37, n. 2, p. 1-37, 2000.

EASTERBY-SMITH, M. et al. Management research an introduction. London: Sage, 2002.

EISENHARDT, K. M. Building theories from case study research. Academy of Management Review, v. 14, n. 4, p. 532-550, 1989.

EMPRESA BRASILEIRA DE PESQUISA AGROPECUÁRIA EMBRAPA. Sistemas de Produção. Disponível em:<http://www. cnpma.embrapa.br>. Acesso em: 28 de Setembro de 2005.

FOOD AND AGRICULTURAL ORGANIZATION - FAO. Tropical Fruits Conpemdium. Disponível em:<http://www.fao.org/es/ESC/ en/20953/21038/index.html>. Acesso em: 27 de Maio de 2007.

FOOD AND AGRICULTURAL ORGANIZATION - FAO. Statistics. Disponível em: <http://www.fao.org/es/ESC/en/20953/21038/ index.html >. Acesso em: 15 de Novembro de 2008.

FARINA, E. M. M. Q.; NUNES, R. A. Evolução do sistema agroalimentar no Brasil e a redução de preços para o consumidor: os efeitos da atuação dos grandes compradores. Working Paper, Cepal/IPEA, 2002. Disponível em: <http://www.cepal.org/brasil >. Acesso em: 12 de Outubro de 2006.

FARINA, M. M. Q. F.; AZEVEDO, P. F.; SAES, S. Competitividade: mercado, estado e organizações. São Paulo: Editora Singular, 1997.

FRESHINFO. Availability. Disponível em: <http://www.freshinfo. com>. Acesso em: 23 de Agosto de 2004.

FULPONI, L. Private voluntary standards in the food system: the perspective of major food retailers in OECD countries. Food Policy, v. 31, n. 1, p. 1-13, 2006.

GARCIA, M.; POOLE, N. The impact of private safety and quality standards for fresh produce exports from Mediterranean countries. London: Food Industry Management Unit, Department of Agricultural Sciences, Imperial College, University of London, 2004. Disponível em: <http://www.imperial.ac.uk/ agriculturalsciences/cfer/>. Acesso em: 13 de Julho de 2004.

GEREFFI, G. International trade and industrial upgrading in the apparel commodity chain. Journal of International Economics, v. 48, n.1, p. $37-70,1999$.

HUMPHREY, J. Shaping value chains for development: global value chains in agribusiness. Eschborn: Deutsche Gesellschaf fur, 2005.
HUMPHREY, J.; SCHMITZ, H. Chain governance and upgrading: tacking stock. In: SCHMITZ, H. (Ed.). Local enterprises in the global economy: issues of governance and upgrading. Cheltenham: Edward Elgar, 2004.

JAFFEE, S.; MASAKURE, O. Strategic use of private standards to enhance international competitiveness: vegetable exports from Kenya and elsewhere. Food Policy, v. 30, p. 316-333, 2005.

KAPLINSKY, R.; MORRIS, M. Handbook for value chain research. Brighton, United Kingdon: Institute of Development Studies, 2001. Disponível em: <http://www.ids.ac.uk>. Acesso em: 20 de Março de 2004. Mimeo.

LAZZARINI, S. G. Estudos de caso: aplicações e limites do método. In: FARINA, E. M. M. Q. (Ed.). Estudos de caso in Agribusiness. São Paulo: Pioneira, 1997.

MALHOTRA, N. Pesquisa de Marketing: uma orientação aplicada. 3 ed. Porto Alegre: Bookman, 2001. 719 p.

MENARD, C. The economics of hybrid organizations. MIT, USA: International Society for New Institutional Economics, 2002.

RAIKES, P.; FRIIS, M.; PONTE, S. Global Commodity chain analysis and the french filière approach: comparison and critique. Copenhague: Centre for Development Research, 2000. (Working Paper 003).

HEADING for Exit. The Economist, v. 380, n. 8489, p. 54, 2006. THE MANGO ASSOCIATION. Disponível em: <http://www.mad4mango. com/mango $>$. Acesso em: 24 de Dezembro de 2005.

UK COMPETITION COMMISSION. Supermarkets: a report on the supply of groceries from multiple stores in the United Kingdom. London: Competition Commission, 2000. Disponível em: <http:// www.competition-commission.org.uk/rep-pub/reports/2000>. Acesso em: 10 de Fevereiro de 2005.

VOSS, C. et al. Case Research in operations management. International Journal of Operations Management, v. 22, n. 2, p. 195-219, 2002.

WILLIAMSON, O. E. Economic Institutions: spontaneous and intentional governance. Jounal of Law, Economics and Organization, v. 7, p. 159-187, 1991.

WILLIAMSON, O. E. The economic institutions of capitalism: firms, markets, relational contracting. New York: Free Press, 1985.

WORTMANN, M. Aldi and the German model: structural change in German grocery retailing and the success of grocery discounters. Competition \& Change, v. 8, n. 4, p. 425-441, 2004.

WORTMANN, M. Structural change and globalisation in the German retail industry. Berlin: Wissenschafszentrum Berlin, 2003. Discussion Paper SP III. Disponivel em: <skylla.wz-berlin. de/pdf/2003/iii03-202b.pdf >. Acesso: 06 de Junho de 2004.

YIN, R. K. Estudo de caso: planejamento e métodos. Porto Alegre: Bookman, 2005.

ZYLBERSZTAJN, D. Estruturas de governança e coordenação do agribusiness: uma aplicação da nova economia das instituições. 1995. 238 p. Tese (Livre Docência em Administração) - FEA/ USP. 


\section{Sobre os autores}

\section{Roberta de Castro Souza}

Centro Universitário da FEI

Av. Humberto de Alencar Castelo Branco, 3972, Bairro Assunção, CEP 09850-901 - São Bernardo do Campo - SP e-mail: csouzaroberta@gmail.com

\section{João Amato Neto}

Departamento de Engenharia de Produção da Escola Politécnica da Universidade de São Paulo Av. Professor Almeida Prado, 128. Tr. 2 Biênio $2^{\circ}$, CEP 05508-900 - São Paulo - SP e-mail: amato@usp.br

Agradecimentos. Os autores agradecem as valiosas sugestões da Profa. Dra. Vivian Lara dos Santos Silva do Departamento de Zootecnia e Engenharia de Alimentos da Universidade de São Paulo (FZEA/USP). 